1 Isotopically labelled nanoparticles at relevant

2 concentrations: how low can we go? - The case of

\title{
$3 \mathrm{CdSe} / \mathrm{ZnS}$ QDs in surface waters
}

4 Nurul I. Supiandi ${ }^{\dagger}$, G. Charron ${ }^{\dagger}$, M. Tharaud ${ }^{\dagger}$, L. Cordier ${ }^{\dagger}$, J.-M. Guigner ${ }^{\Delta}$, M. F. Benedetti ${ }^{\dagger}$ and

$5 \quad Y$. Sivry $^{\dagger *}$

$6 \uparrow$ Institut de Physique du Globe de Paris, Sorbonne Paris Cité, Univ. Paris Diderot,

$7 \quad$ UMR 7154, CNRS, F-75005 Paris, France

8 \& Laboratoire Matière et Systèmes Complexes (MSC), UMR 7057, Université Paris Diderot,

9 Sorbonne Paris Cité, 75013 Paris, France

$10 \Delta$ Institut de Minéralogie, de Physique des Matériaux et de Cosmochimie (IMPMC), 75005 Paris,

11 France

12 KEYWORDS: detection limits, nanoparticles, isotopic labelling, quantum dots, aquatic matrices,

13 HR-ICP-MS 
15 ABSTRACT. Analytical barriers impose to work at nanoparticles (NPs) concentration orders of 16 magnitude higher than the expected NPs concentrations in the environment. To overcome these

17 limitations, the use of non-traditional stable isotope tracers incorporated in NPs (spiked-NPs)

18 coupled with HR-ICP-MS has been proposed. The performance and efficiency of this analytical

19 method was assessed in the case of quantum dots (QDs). Multi-isotopically labelled

$20{ }^{111} \mathrm{Cd}^{77} \mathrm{Se} /{ }^{68} \mathrm{ZnS}$ QDs were synthesized and their dissemination in natural aquatic matrices (river,

21 estuarine and sea waters) was modelled at very low concentrations (from 0.1 to $5000 \mathrm{ppt}$ ). The QD

22 limits of quantification (QD-LOQ) in each matrix were calculated according to the isotopic tracer.

23 In ultrapure and simple medium $\left(\mathrm{HNO}_{3} 2 \%\right), \mathrm{Zn}, \mathrm{Cd}$ and $\mathrm{Se}$ originated from the QDs were

24 quantifiable at concentrations of $10,0.3$ and $6 \mathrm{ppt}$, respectively, which is lower than the

25 conventional HR-ICP-MS LOQs. In aquatic matrices, the QD-LOQs increase 10-, 130-, and 250-

26 fold for $\mathrm{Zn}, \mathrm{Cd}$, and Se, respectively, but remain relevant of environmental concentrations (3.4 ppt

$27 \leq$ QD-LOQs $\leq 2.5 \mathrm{ppb}$ ). These results validate the use of isotopically-labelled ENPs at relevant

28 concentrations in experimental studies related to either their fate, behavior or toxicity in most

29 aquatic matrices. 


\section{INTRODUCTION}

32 Engineered nanoparticles (ENPs) are widely used in various consumer products due to their

33 exceptional chemical, optical, magnetic or mechanical properties. ${ }^{1}$ To name a few, $\mathrm{TiO}_{2} \mathrm{NPs}$ are

34 used as photocatalyst in water and air treatment, ${ }^{2}$ or as whitening agent in paints and in food and

35 food packaging products, ${ }^{3-5} \mathrm{Ag}$ NPs are added to fabrics for anti-bacterial purpose, ${ }^{6-12} \mathrm{ZnO}$ NPs

36 act as UV absorbers in sunscreens, ${ }^{13-15}$ and $\mathrm{CeO}_{2}$ NPs are incorporated in catalytic converters in

37 the automotive industry. ${ }^{16}$ Quantum dots (QDs), namely fluorescent nanocrystals made of semi-

38 conducting materials, are used in lightning and light display devices for color and brightness

39 enhancement, in solar panels and bio-sensors. ${ }^{17-22}$ The use and disposal of these products leads to

40 the release of nanomaterials in wastewater or in the environment (e.g. surface waters, soils).

41 Surface waters which are known as one of the major vectors of ENPs dispersion in environment, ${ }^{23}$

42 have inspired numerous publications aiming at determining ENPs fate and behavior in surface

43 waters, in particular through assessing their colloidal and chemical stabilities. ${ }^{24-30}$ However, these

44 physico-chemical studies were often conducted at ENPs concentrations that are orders of

45 magnitude higher than the levels expected from their dissemination in aquatic environments. The

46 concentration of ENPs has been shown to affect their dissolution and their aggregation state,

47 thereby potentially impacting their behavior. For instance, the increase in ZnO NPs concentrations

48 decreased their dissolution, ${ }^{31}$ whereas their homoaggregation increased with increasing

49 concentrations. ${ }^{32}$ Therefore, working at environmentally relevant concentrations is critical when

50 studying the fate and behavior of ENPs in natural systems.

51 Nevertheless, working at realistic concentrations also means overcoming two common analytical

52 barriers: i) unsuitable instrumental detection limits and ii) the geochemical environmental 
53 background, i.e. the natural occurrence of some constitutive elements of the ENPs in the

54 environment. Recent development of methods such as single counting ICP-MS (sp-ICP-MS) allow

55 the detection of NPs with limit of detections achieving ppt levels. However, when studying the

56 behavior (e.g. dissolution) of a type of NPs in an environmental medium e.g. river/seawater

57 containing already the same constitutive elements as the NPs, sp-ICP-MS will not be able

58 distinguishing between natural and anthropogenic nanomaterial. Hence, recent studies have

59 proposed the use of non-traditional stable isotopes to overcome these analytical barriers, i.e. the

60 use of isotopically modified or "spiked" ENPs which can be quantified by Inductively Coupled

61 Plasma Mass Spectrometry (ICP-MS). ${ }^{33-37}$ For instance, this strategy was employed to determine

62 the bio-uptake of $\mathrm{TiO}_{2}, \mathrm{Ag}$, and $\mathrm{ZnO}$ NPs in aquatic organisms, using ${ }^{47} \mathrm{Ti},{ }^{109} \mathrm{Ag},{ }^{67} \mathrm{Zn}$ tracers,

63 respectively. ${ }^{33,38,39}$ Quantitative detection of the ENPs was achieved at concentrations as low as

$645 \mathrm{ppb}, 6 \mathrm{ppt}$, and $1 \mathrm{ppm}$ for ${ }^{47} \mathrm{TiO}_{2},{ }^{109} \mathrm{Ag}$, and ${ }^{67} \mathrm{ZnO} \mathrm{NPs}$, respectively, showing the advantages

65 of ENPs isotopic labelling. Although the necessity to work at realistic concentrations has been

66 recently discussed, ${ }^{37-39}$ the exposure concentrations generally used in many ENPs fate and behavior

67 studies remain higher than the estimated ones in natural media and, so far, none has tried to

68 accurately determine to which extent the labelling of ENPs with stable isotopes would allow to

69 work at the cutting edge of analytical barriers in ENPs fate and behavior studies.

70 In the present study, we aimed to determine for the first time the analytical limits of the ENP

71 isotopic labelling technique in aquatic matrices (river, estuarine, and seawaters). Quantum dots

72 with a $\mathrm{CdSe} / \mathrm{ZnS}$ core/shell structure enriched in ${ }^{111} \mathrm{Cd},{ }^{77} \mathrm{Se}$, and ${ }^{68} \mathrm{Zn}$ (hereafter called multispiked

73 QDs) were synthesized for the first time in this study. Even though the estimated QDs concentration

74 in aquatic environment is less than 1 ppt, ${ }^{40,41}$ their increasing environmental release will 
75 unavoidably follow due to the increasing presence of QDs in consumer products, especially

76 electronic devices (e.g. TV set or light bulbs) - therefore, CdSe/ZnS QDs make for a worthy

77 analytical case. As a representative example of core/shell-structured nanomaterials, their reactivity

78 is expected to be more complex than that of homogeneous NPs. These ENPs make for a challenging

79 system on which to gauge the analytical limits of the isotopic labelling strategy. These multispiked

80 QDs were then dispersed at very low and environmentally relevant concentrations (ppt-ppb) into

81 the chosen aquatic matrices. Measurements by HR-ICP-MS and subsequent chemometric

82 processing allowed to accurately determine the limits of quantifications according to the element

83 labelled and to the matrix composition (QD-LOQ). Chemometrics was proven to be an efficient

84 analytical approach e.g. during method optimization. ${ }^{42}$ This work is expected to provide valuable

85 basis to any future study aiming at using isotopically labelled ENPs to determine their fate,

86 behavior, or toxicity in natural media while working at relevant concentrations.

88 MATERIALS AND METHODS

89 Composition of aquatic matrices

90 The Seine river water was chosen first, as it is highly representative of both a natural carbonate-

91 rich system and a highly anthropized watershed, which is relevant next to the possibility of an

92 accidental release of ENPs. The Seine river water sample was collected behind the University

93 Pierre et Marie Curie (Quai Saint-Bernard, Jardin Tino Rossi, Paris, France, $48.8475^{\circ} \mathrm{N}, 2.3614^{\circ}$

94 E), and filtered through a $0.2 \mu \mathrm{m}$ cellulose acetate membrane, stored in pre-cleaned, acid-washed

95 polyethylene bottles and divided in three subsamples for: i) major and trace elemental analyses,

96 where the aliquot was acidified with $15 \mathrm{~N}$ distilled nitric acid to obtain $2 \%$ of nitric acid in the 
97 samples, ii) analysis of anions $\left(\mathrm{Cl}^{-}, \mathrm{SO}_{4}{ }^{2-}, \mathrm{NO}_{3}{ }^{-}\right)$, and iii) the determination of isotopic labelling

98 limits experiments. Sampling and analytical procedures were described by Benedetti et al. ${ }^{43}$ The 99 chemical composition of the Seine water sample is displayed in Table S1.

100 The second surface water chosen was a synthetic seawater (SW), prepared following the 101 American Society for Testing and Materials (ASTM) International guidelines (Table S2).

102 Dissolved $\mathrm{Zn}, \mathrm{Cd}$ and Se with natural isotopic abundances were also added to this SW at 103 concentrations provided by Seine Normandie Water Agency. ${ }^{44}$

104 Afterwards, from the precedent Seine river water and SW, three different solutions of estuarine 105 waters were prepared by mixing the Seine river water sample and the SW solution (V/V) by the 106 ratios 75:25 (estuarine water 1), 50:50 (estuarine water 2), and 25:75 (estuarine water 3). All waters 107 were stored at $4^{\circ} \mathrm{C}$ in pre-cleaned, acid-washed polyethylene bottles.

109 Synthesis of multi-isotopically labelled CdSe/ZnS quantum dots

110 All chemical products with natural isotopic composition were purchased from Sigma Aldrich: 111 sulfur (S, 99.9\%, powder), oleic acid (OA, technical, 90\%), trioctylphosphine (TOP, 90\%), 1112 octadecene (ODE, 90\%), chloroform $\left(\mathrm{CHCl}_{3}, 99 \%\right)$, and thioglycolic acid (TGA, 99\%). Chemicals 113 with modified isotopic composition were purchased from ISOFLEX USA: cadmium oxide (CdO 114 powder) enriched at $96.00 \%$ in ${ }^{111} \mathrm{Cd}$, zinc oxide ( $\mathrm{ZnO}$ powder) enriched at $99.16 \%$ in ${ }^{68} \mathrm{Zn}$, and 115 selenium (Se powder) enriched at $99.20 \%$ in ${ }^{77} \mathrm{Se}$.

116 A common route towards $\mathrm{CdSe} / \mathrm{ZnS}$ nanocrystals consists in nucleating CdSe cores by quickly 117 injecting a chalcogenide mixture into a hot organic solution of the metal salts in a process known 118 as the hot injection method. The growth of the $\mathrm{ZnS}$ shell is either achieved in a subsequent step or 
119 one-pot in the same step as nucleation, as described by Bae et al. ${ }^{45}$ In this protocol, cadmium oxide,

120 zinc acetate, elemental selenium and elemental sulfur were used as the metal and chalcogen

121 precursors, respectively. Transposing this route to multi-spiked CdSe/ZnS QDs raised difficulties

122 regarding the availability of isotopically-modified precursors of suitable isotopic enrichments.

$123{ }^{111} \mathrm{CdO}$ and ${ }^{77} \mathrm{Se}$ powders were commercially available with ${ }^{111} \mathrm{Cd}$ and ${ }^{77} \mathrm{Se}$ abundances markedly

124 different from the natural ones $(96.00 \%$ and $99.20 \%$, respectively) that could impart a high isotopic

125 contrast to the QDs compared to the natural background. However, zinc acetate was commercially

126 available with a $48 \%{ }^{68} \mathrm{Zn}$ abundancy only, which did not contrast enough with the $18 \%$ natural

127 abundancy to support detection of the spiked QDs in the ppt range in natural matrices. Therefore,

128 Bae's protocol was adapted to start from $\mathrm{ZnO}$ as the zinc precursor, as it was commercially

129 available with $99.16 \%$ enrichment in ${ }^{68} \mathrm{Zn}$.

130 Multi-spiked CdSe/ZnS QDs were synthesized by the hot injection method in octadecene

131 following an adaptation of the protocol from Bae et al. ${ }^{45}$ The modification consisted in substituting

$132{ }^{68} \mathrm{Zn}$-enriched $\mathrm{ZnO}$ for the initial zinc acetate precursor which was not available with a suitable

133 modified isotopic composition. ${ }^{45}$ Briefly, $51.364 \mathrm{~g}(0.4 \mathrm{mmol})$ of ${ }^{111} \mathrm{Cd}$-enriched $\mathrm{CdO}, 325.56 \mathrm{~g}$

134 (4 mmol) of ${ }^{68} \mathrm{Zn}$-enriched $\mathrm{ZnO}, 6.746 \mathrm{~g}(23.88 \mathrm{mmol})$ of oleic acid, $20 \mathrm{mg}(0.2 \mathrm{mmol})$ of succinic

135 anhydride and $23 \mathrm{~mL}$ octadecene were placed in a $100 \mathrm{~mL}$ three-necked round bottom flask

136 equipped with a temperature probe, a coil condenser and connected to an inert lane. The flask was

137 nested into a heating mantel whose power was controlled by a temperature controller connected to

138 the temperature probe. The mixture was degassed under $10 \mathrm{mbar}$, heated to $150^{\circ} \mathrm{C}$ and maintained

139 under these conditions for 20 min. Next, the montage was filled with $\mathrm{N}_{2}$ and further heated to

$140180^{\circ} \mathrm{C}$ for $10 \mathrm{~min}$ and then $250^{\circ} \mathrm{C}$ for 10 more minutes to fully dissolve the $\mathrm{ZnO}$ powder. The 
141 temperature was then increased to $310^{\circ} \mathrm{C}$. At this temperature, a mixture of $31.584 \mathrm{mg}(0.4 \mathrm{mmol})$

142 of ${ }^{77} \mathrm{Se}$-enriched selenium and $128.28 \mathrm{mg}(4 \mathrm{mmol})$ sulfur dissolved in $3 \mathrm{~mL}$ of trioctylphosphine

143 under $\mathrm{N}_{2}$ atmosphere was quickly injected into the reaction flask under vigorous stirring.

144 Immediately after injection, the temperature was lowered to $300^{\circ} \mathrm{C}$ and the flask was kept at this

145 temperature for $15 \mathrm{~min}$ to promote the growth of the nanocrystals. The flask was then cooled down

146 to room temperature. The QDs were precipitated with $100 \mathrm{~mL}$ of acetone by centrifugation at 6000

$147 \mathrm{rpm}$ and then purified to remove excess reactants by redispersion-precipitation cycles twice with

$14890 \mathrm{~mL}$ acetone and once with $40 \mathrm{~mL}$ methanol.

149 Then, water-soluble QDs were prepared by replacing the oleic acid ligands attached to the surface 150 of the QDs with thioglycolic acid (TGA). In a 100-mL round bottom flask, a solution of $10 \mathrm{~mL}$ of

151 chloroform and $1.6 \mathrm{~mL}$ of thioglycolic acid (TGA) was prepared. Next, the flask was nested into 152 an ultrasonic bath and $460 \mu \mathrm{L}$ of the multi-spiked QDs stock solution were added under sonication 153 and maintained under sonication for $1 \mathrm{~min}$. The flask was then equipped with a condenser and 154 transferred into a water bath. The reaction mixture was stirred using a stir bar and heated under 155 reflux for 2 hours. After cooling to room temperature, the TGA-coated QDs were precipitated by 156 centrifugation at $6000 \mathrm{rpm}$ and then purified by redispersion-precipitation cycles twice with $10 \mathrm{~mL}$ 157 chloroform and once with $10 \mathrm{~mL}$ acetone. Finally, the TGA-coated QDs were dispersed in $\mathrm{pH} 8$ 158 borate buffer and purified using Centricon ${ }^{\circledR}$ Centrifugal Filter Units (30kD MWCO) by 159 exchanging the solvent once with a fresh portion of $\mathrm{pH} 8$ borate buffer and 4 times with ultrapure 160 water adjusted at $\mathrm{pH} 10$. The final solution had a volume of $10 \mathrm{~mL}$. 
163 Optical characterization of QDs was carried out by measuring the UV-vis absorption spectra of

164 the TGA-coated QDs stock solution with Thermo Scientific Evolution ${ }^{\mathrm{TM}} 600 \mathrm{UV}-$ vis spectrometer.

165 The fluorescence signal was collected using the Horiba Scientific FluoroMax ${ }^{\circledR}-4$

166 spectrofluorometer.

167 Diluted suspensions QDs were deposited on copper grid to observe their sizes and shapes by

168 Transmission Electron Microscopy (TEM), using a JEOL 2100F electron microscope operating at

$169200 \mathrm{kV}$ and equipped with a field emission gun, a high-resolution UHR pole piece and a Gatan GIF

1702001 imaging filter. To perform chemical analysis, this microscope was coupled with electron-

171 dispersive X-ray spectroscopy (EDXS) using a JEOL detector with an ultrathin window allowing

172 detection of low atomic mass elements. TEM pictures were analysed with the software ImageJ

$1731.51 n$.

174 The total concentrations of $\mathrm{Cd}, \mathrm{Se}$, and $\mathrm{Zn}$ in the TGA-coated QDs stock solution were measured

175 by ICP-OES (Thermo Scientific iCAP 6000 Series) after a complete acid digestion with $\mathrm{HF} / \mathrm{HNO}_{3}$

176 (see protocol in SI) and then after simple acidification (2\% of nitric acid) to evaluate the necessity

177 of using complete acid digestion for all experimental samples.

178

179 Model dissemination of QDs in aquatic matrices

180 All materials used in these experiments (PP tubes, bottles and pipette tips) were washed with

$181 \mathrm{HCl} 1 \mathrm{~N}$ to eliminate possible contaminations in trace metals, especially $\mathrm{Zn}, \mathrm{Cd}$ and $\mathrm{Se}$.

182 TGA-coated $\mathrm{CdSe} / \mathrm{ZnS}$ quantum dots were added separately in all 5 selected natural surface 183 waters, at target concentrations varying from 0.1 to $5000 \mathrm{ppt}$ of $\mathrm{Zn}$ issued from the QDs, resulting 
184 in 0.03 to $1500 \mathrm{ppt}$ in $\mathrm{Cd}$ and 0.02 to $1000 \mathrm{ppt}$ in Se. These choices are in the lowest relevant range

185 of the ENPs estimated concentrations in surface waters (ppt to ppb levels). ${ }^{40}$ The QDs were also

186 added, with the same target concentrations, in both $\mathrm{HNO}_{3} 2 \%$ and $\mathrm{NaNO}_{3} 0.01 \mathrm{M}$, used as control

187 media, since there is no occurrence of natural $\mathrm{Zn}, \mathrm{Cd}$ and $\mathrm{Se}$ in both solutions, and the

$188 \mathrm{NaNO}_{3} 0.01 \mathrm{M}$ solution is representative of the highest typical ionic strength found in river and

189 estuarine waters. ${ }^{46}$ All samples were triplicated to assess the experimental reproducibility.

190 After QDs addition to these media, all samples were agitated then acidified to obtain $2 \%$ of nitric

191 acid in the samples, then left overnight prior to dilution and analysis. Simple acidification was

192 sufficient to completely dissolve the QDs, thus the complete acid digestion with $\mathrm{HF} / \mathrm{HNO}_{3}$ was not

193 further performed. The acidification step is representative of the final step used in many studies

194 prior to ENPs analysis. ${ }^{26,27}$ For $\mathrm{HNO}_{3} 2 \%, \mathrm{NaNO}_{3} 0.01 \mathrm{M}$ matrices and Seine river water sample,

195 no further dilution was needed prior the HR-ICP-MS analysis. For synthetic seawater and estuarine

196 water samples, 50 -fold dilutions were performed for best instrument performance and stability. ${ }^{47}$

198 Quantitative analysis by ICP-MS

199 External standard solutions containing 1, 5, 10, 100, 500, 1000 and 5000 ppt of total Cd, Se and $200 \mathrm{Zn}$ were prepared in $\mathrm{HNO}_{3} 2 \%$. During the whole analysis, a solution containing $5 \mathrm{ppb}$ of rhodium

$201\left({ }^{103} \mathrm{Rh}\right)$ prepared in $\mathrm{HNO}_{3} 2 \%$ was used as internal standard solution to correct from instrumental

202 drift and mass bias, and connected online to the sample tubing using a T-adaptor. The isotopes of $203 \mathrm{Cd}\left({ }^{106} \mathrm{Cd},{ }^{108} \mathrm{Cd},{ }^{110} \mathrm{Cd},{ }^{111} \mathrm{Cd},{ }^{112} \mathrm{Cd},{ }^{113} \mathrm{Cd},{ }^{114} \mathrm{Cd}\right.$ and $\left.{ }^{116} \mathrm{Cd}\right), \mathrm{Zn}\left({ }^{64} \mathrm{Zn},{ }^{66} \mathrm{Zn},{ }^{67} \mathrm{Zn},{ }^{68} \mathrm{Zn}\right.$ and $\left.{ }^{70} \mathrm{Zn}\right)$, 204 and $\mathrm{Se}\left({ }^{74} \mathrm{Se},{ }^{76} \mathrm{Se},{ }^{77} \mathrm{Se},{ }^{78} \mathrm{Se},{ }^{80} \mathrm{Se},{ }^{82} \mathrm{Se}\right.$ ) were analyzed with HR-ICP-MS (ThermoScientific 205 Element II). The isotopes ${ }^{105} \mathrm{Pd},{ }^{115} \mathrm{In},{ }^{118} \mathrm{Sn},{ }^{60} \mathrm{Ni}$ and ${ }^{72} \mathrm{Ge}$ were also analyzed to correct possible 
206 isobaric interferences. ${ }^{48}$ Each intensity used for data treatment corresponds to the average of 15

207 blocks of 3 replicate measurements, allowing an internal reproducibility with standard error better

208 than 5\%. Within each session, reproducibility of the multi-element reference material (TM-23.4

209 Lake Ontario water from National Research Council Canada) was checked at the beginning and 210 the end of each analysis sequence and yielded on average $6.6 \%$ shift from the certified values. Most

211 of the sub-procedural variation was found to be within the methods stated overall external

212 reproducibility ${ }^{49}$ determined on the three experimental replicates.

214 Calculation of spiked QDs concentrations

215 The contrast in isotopic compositions between the multi-spiked QDs and the natural background

216 forms the basis of the quantification of the QDs from HR-ICP-MS measurements. The calculation

217 is an adaptation from Dybowska et al. ${ }^{33}$ and is detailed in SI.

219 RESULTS AND DISCUSSION

220 QDs synthesis and characterization

221 Prior to the synthesis of multi-spiked QDs, the synthesis protocol was first conducted as a test

222 run using non-isotopically enriched precursors. Green QDs with an emission centered at $540 \mathrm{~nm}$

223 were obtained. Their absorption spectrum features well resolved excitonic peaks and their emission

224 peak has a full width at half maximum (FWHM) of $35 \mathrm{~nm}$, which is in good agreement with the

225 observations of Bae et al. (see SI, Figure S1). When the synthesis was conducted with the 226 isotopically enriched precursors, difficulties were encountered regarding the dissolution of the $\mathrm{ZnO}$

227 precursor. To fully dissolve the powder, it was necessary to heat the metal precursor solution up to 
$228250^{\circ} \mathrm{C}$ and to maintain it at this temperature for 10 minutes. The resulting multi-spiked QDs also

229 have a green emission centered at $540 \mathrm{~nm}$, however the excitonic peaks are damped and the

230 emission linewidth increases to $40 \mathrm{~nm}$ (Figure 1a), indicating that the quality of the nanocrystals

231 has degraded slightly compared to that of the test run QDs. Nevertheless, those properties are still

232 comparable to the QDs described in the original report. The QDs size distribution estimated from

233 a TEM image was $7.9 \pm 1.1 \mathrm{~nm}$ for $n=250$ (Figure $1 \mathrm{~b}$ and c). An EDXS spectrum is provided in

234 SI (Figure S2) confirming the presence of $\mathrm{Zn}, \mathrm{Cd}$, and $\mathrm{Se}$ in the QDs.

235 To allow QDs dissemination in aqueous matrices, the QDs were functionalized by substituting

236 thioglycolic acid (TGA) with the oleic acid ligands stemming from the initial synthesis. TEM

237 images are provided in SI (Figure S2). The final TGA-coated QDs stock solution in $\mathrm{pH} 10$ water

238 contains $101.1 \pm 1.0 \mathrm{ppm}$ of $\mathrm{Zn}, 31.8 \pm 0.3 \mathrm{ppm}$ of Cd, $19.2 \pm 0.3 \mathrm{ppm}$ of Se, and $404 \pm 41 \mathrm{ppm}$ of

239 S by ICP-OES.

240
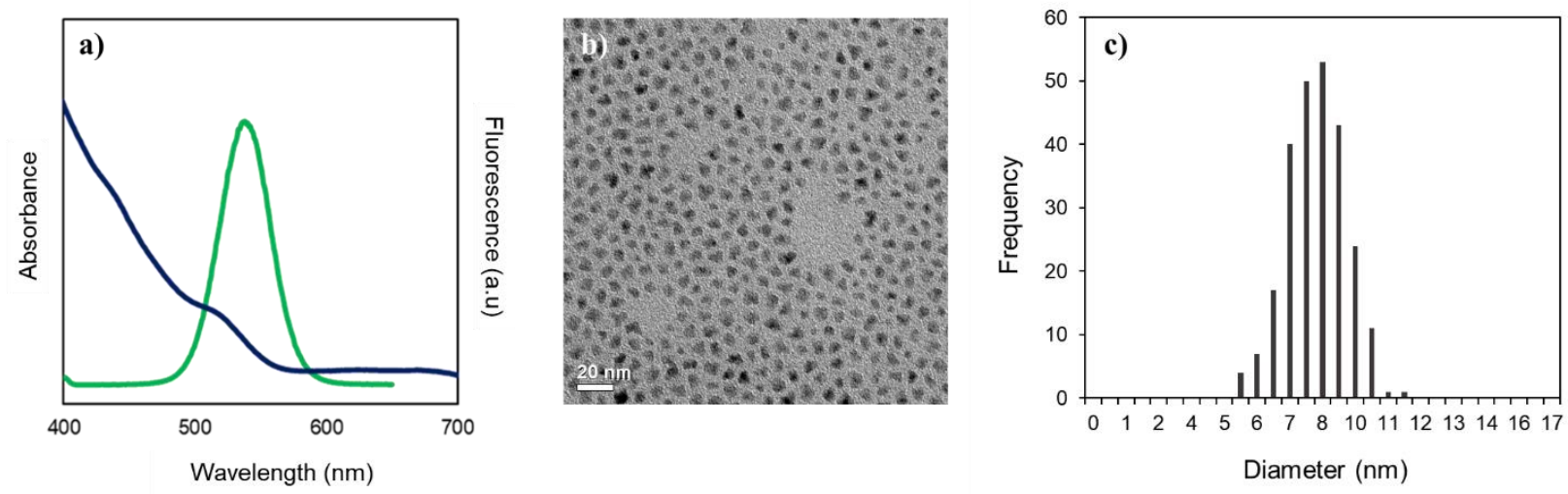

242 Figure 1. a) UV-vis absorption spectrum (blue line) of the multi-spiked quantum dots and

243 corresponding fluorescence emission spectrum (green line) under $400 \mathrm{~nm}$ excitation; b) TEM 
244 image of CdSe/ZnS QDs dispersed in chloroform; c) Size distribution of the QDs estimated from 245 the TEM image.

247 The isotopic compositions of the multi-spiked QDs regarding $\mathrm{Zn}, \mathrm{Cd}$ and Se were assessed by 248 HR-ICP-MS and compared to the natural ones (Figure S3). The multi-spiked QDs feature 95.89, 24999.11 and $98.95 \%$ enrichments in ${ }^{111} \mathrm{Cd},{ }^{68} \mathrm{Zn}$ and ${ }^{77} \mathrm{Se}$ respectively. These abundances are slightly 250 lower than those certified by ISOFLEX for the starting materials, most probably because of minor 251 contamination by chemicals during the synthesis steps. Nevertheless, the QD modified isotopic 252 composition is in sharp contrast with that of the natural background $(12.80 \%, 18.80 \%$, and $7.64 \%$ 253 for ${ }^{111} \mathrm{Cd},{ }^{68} \mathrm{Zn}$ and ${ }^{77} \mathrm{Se}$ respectively).

255 Assessment of analytical performances

256 Recovery plots were built by representing the QDs concentration estimated using Eq. S8 257 (hereafter referred to as predicted concentration) as a function of the theoretically known 258 concentrations of QDs added in different matrices (reference concentration in the following), as 259 exemplified in the case of the Seine matrix and on the basis of the ${ }^{68} \mathrm{Zn}$ tracer in Figure 2. 


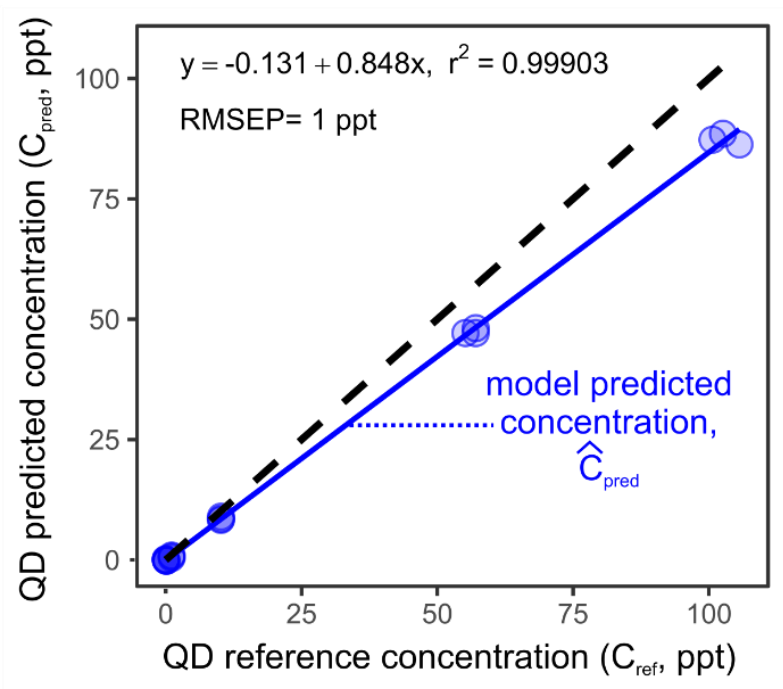

262 Figure 2. $C_{\text {pred }}$ vs. $C_{\text {ref }}$ recovery plots for estimations of QDs concentration based on the ${ }^{68} \mathrm{Zn}$ 263 tracer. The plain blue line indicates the best linear fit and the dashed black line the ideal $C_{\text {pred }}=$ $264 C_{\text {ref }}$ recovery plot.

266 The slope of the best linear regression model leads to the recovery rate of the analytical method, 267 namely the fraction of detected QDs amongst the QDs actually present in the sample (which is 268 related to the bias by Bias $=(1-$ Recovery $) \times 100)$. The precision on the predicted QD 269 concentration was estimated from the Root Mean Square Error of Prediction (RMSEP, defined in 270 Eq. 1) of the regression model. The limit of quantification was chosen as the concentration for 271 which the risk of reporting a false positive or a false negative falls below $0.1 \%$. Briefly, for a set 272 of samples with reference concentration $\mathrm{C}_{0}, \mathrm{C}_{1}, \mathrm{C}_{2}, \ldots, \mathrm{C}_{\mathrm{n}}$ where $\mathrm{C}_{0}$ corresponds to the "blank" 273 samples, i.e. to pure matrix samples, the QD-LOQ was practically determined as follows. A t-test 274 was performed to compare the mean value of the predicted concentrations for the blank samples 275 with that of the predicted concentrations for the samples having the reference concentration $\mathrm{C}_{1}$. If 
276 the t-test concluded that the two means were significantly different at the $99.9 \%$ confidence level,

277 then $\mathrm{C}_{1}$ was designated as the QD-LOQ. If not, then the t-test was conducted using the samples

278 having $\mathrm{C}_{2}$ concentration. The process was repeated with increasing $\mathrm{C}_{\mathrm{i}}$ concentrations until the

279 calculated $t$ value exceeded the critical $t$-value at the $99.9 \%$ confidence level (Figure 3 ). Since our

280 set of QD spiked samples covers several decades, there are only few experimental points in the

281 vicinity of the QD-LOQ. The QD-LOQ determined from the series of t-test conducted on the 282 experimental data then corresponds to an overestimation of the true QD-LOQ. Therefore, a second

283 series of t-tests were conducted using the experimental blank samples and the model predicted

284 values at intermediate concentrations (with $\widehat{C_{l, p r e d}}$ as the mean and RMSEP as the standard

285 deviation). This estimation is also conservative since it assigns overestimated standard deviations

286 to points at low reference concentrations as the RMSEP is calculated from data covering several

287 decades. The lowest of the two estimates of QD-LOQ was therefore retained.

$$
R M S E P=\sqrt{\frac{\sum\left(C_{\text {pred }, i}-\hat{C}_{\text {pred }, i}\right)^{2}}{n}} \text { where } \mathrm{n} \text { is the number of samples. }
$$

Eq. 1 


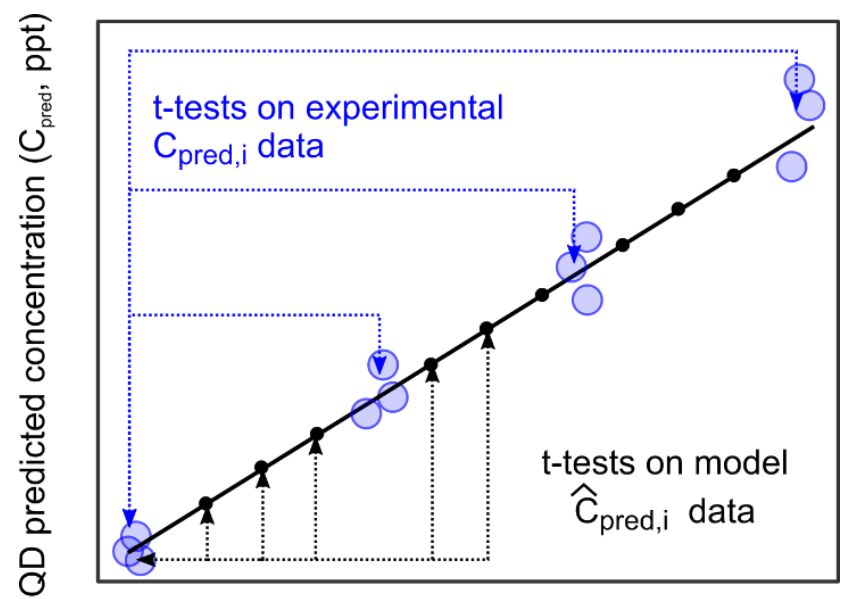

293 Figure 3. Overview of methodology applied to estimate the QD-LOQ from the recovery plot or its 294 model.

296 The recovery plots for the ${ }^{68} \mathrm{Zn},{ }^{111} \mathrm{Cd}$ and ${ }^{77} \mathrm{Se}$ in all investigated matrices are presented in SI 297 (Figures S5 to S24), along with the intensity vs. isotope concentration calibration plots that were 298 used to build them. The biases of all recovery plots are also summarized in SI (Table S3). The $t$ 299 values for different QDs concentrations in $\mathrm{Cd}, \mathrm{Zn}$ and Se calculated in all five matrices are also 300 provided in SI (Table S5 to S7).

\section{Analytical performances: $Q D-L O Q$ and precision}

303 Figure 4a displays the observed recovery rates by element. The recovery rates for $\mathrm{Cd}$ and $\mathrm{Zn}$ are 304 excellent at $99 \pm 14 \%$ and $97 \pm 13 \%$ on average for all investigated matrices. However, the 305 recovery rate for Se is poor at $19 \pm 8 \%$, indicating that the method lacks sensitivity when the ${ }^{77} \mathrm{Se}$ 306 tracer is used. This is related to the instrumental resolutions at which the three different elements 307 were measured. Briefly, Cd isotopes were measured in low resolution (LR) since this element is 
308 not strongly impacted by polyatomic or isobaric interferences. $\mathrm{Zn}$ isotopes had to be measured in

309 middle resolution $(\mathrm{MR})$ to solve polyatomic interference issues $\left(e . g .{ }^{48} \mathrm{Ca}^{16} \mathrm{O}^{+},{ }^{32} \mathrm{~S}^{16} \mathrm{O}^{18} \mathrm{O}^{+}\right.$,

$310{ }^{40} \mathrm{Ar}^{14} \mathrm{~N}_{2}^{+}$), resulting in counts numbers about $10 \%$ of those typically measured in LR. In the case

311 of Se, it was necessary to perform the measurements in high resolution (HR) to overcome

312 polyatomic interferences mostly caused by argon (Ar), e.g. ${ }^{36} \mathrm{Ar}^{40} \mathrm{Ar}^{1} \mathrm{H}^{+}, 40 \mathrm{Ar}_{2}{ }^{+}$, due to the use of

313 Ar as the plasma gas. The intensity signal measured is then around $3 \%$ of the total signal measured

314 in LR, which is related to the resolution slit width defining the mass resolution, $R\left(R_{L R}=300, R_{M R}\right.$

$315=4000$, and $\mathrm{R}_{\mathrm{HR}}=10000$ ). An ANOVA calculation on a model describing the recovery rate as a

316 linear function of the ICP resolution confirmed that the resolution had a significant impact at the

$31799.9 \%$ confidence level (Tables S9 and S10, model M1). Count numbers were furthered lowered

318 by the fact that the QD concentrations in term of Se were about 2 and 6 times lower on average

319 than that of $\mathrm{Cd}$ and $\mathrm{Zn}$ respectively. The unsatisfactory results obtained in the case of Se highlight

320 the limits of the spiking method for tracking NPs: for elements subjected to strong polyatomic

321 interferences, it will not be possible to access spike concentrations below the ppb level. However,

322 some specific technical solutions such as hydride generation ${ }^{50}$ could allow overcoming this

323 limitation. 

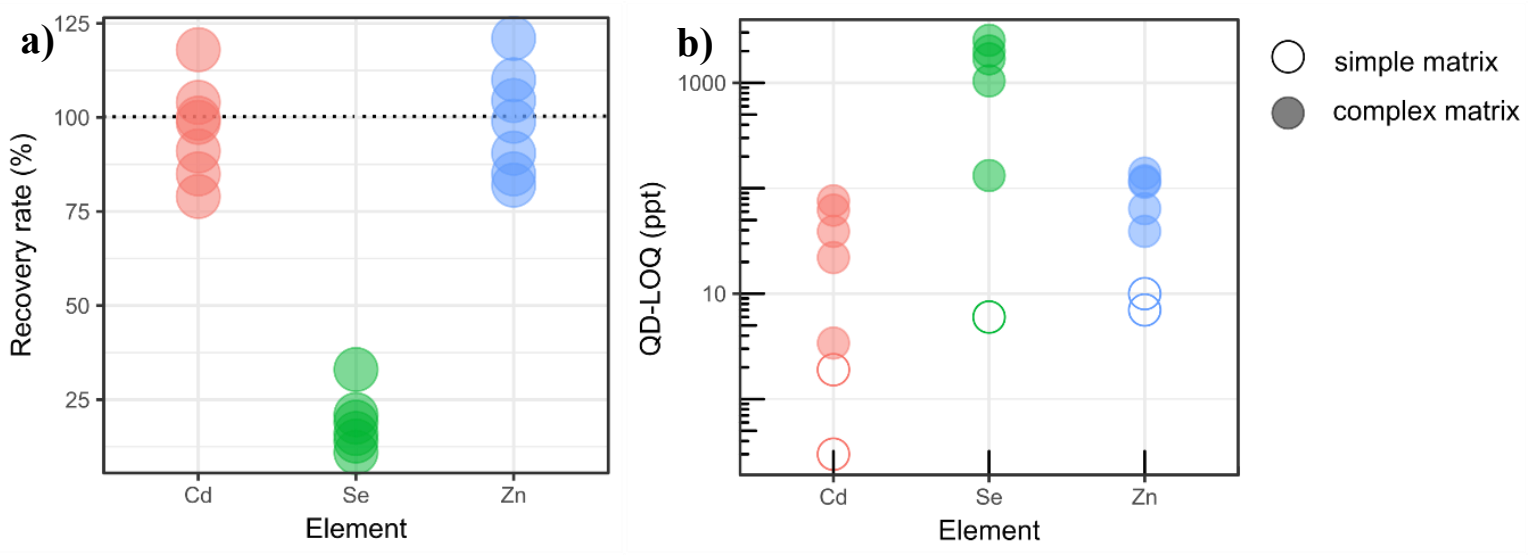

326 Figure 4. Recovery rates grouped by tracer element, for all matrices confounded (a) and QD-LOQs

327 grouped by tracer element, for simple matrices (empty symbols) and complex matrices (filled 328 symbols) (b).

330 Figure 4b and Table 1 display the QD-LOQs of the multi-spiked QDs grouped by tracer element.

331 In oversimplified media $\left(\mathrm{HNO}_{3} 2 \%\right.$ and $\left.\mathrm{NaNO}_{3} 0.01 \mathrm{~N}\right)$ where the background levels in $\mathrm{Zn}, \mathrm{Cd}$, 332 and Se are below the HR-ICP-MS LOQ (30, 3, and 62 ppt for Zn, Cd and Se, respectively), the 333 QD-LOQ of $\mathrm{Zn}, \mathrm{Cd}$, and Se were 10, 0.3, and $6 \mathrm{ppt}$, respectively, and in $\mathrm{NaNO}_{3} 0.01 \mathrm{~N}$ were 7 and 3342 ppt for $\mathrm{Zn}$ and $\mathrm{Cd}$, respectively. In contrast, in complex matrices such as Seine river water, the 335 QD-LOQZn increases to $39 \mathrm{ppt}$. In estuarine water 1 (Seine/SW 75:25), estuarine water 2 336 (Seine/SW 50:50), estuarine water 3 (Seine/SW 25:75), and SW, the QD-LOQzn increases to 139, 337 118, 64, and 112 ppt, respectively. The QD-LOQ in Seine, estuarine water 1, 2, 3, and SW, were $3383.4,22,39,76$, and $62 \mathrm{ppt}$, respectively for $\mathrm{Cd}$ and 132, 1044, 2534, 2003, and $1689 \mathrm{ppt}$, 339 respectively for Se. 
341 Table 1. GBC, QD-LOQ, precision (RMSEP), and RLOQ in different matrices. The conventional

342 HR-ICP-MS LOQ are: Zn 30 ppt, Cd 3 ppt, Se 60 ppt. n.a.: not available.

\begin{tabular}{|c|c|c|c|c|c|c|c|c|}
\hline & & & $\mathrm{NaNO}_{3}$ & & Seine/SW & Seine/SW & Seine/SW & \\
\hline & & $\mathrm{HNO}_{3} 2 \%$ & $10^{-2} \mathrm{M}$ & Seine & $75: 25$ & $50: 50$ & $25: 75$ & $\mathrm{SW}$ \\
\hline \multirow{4}{*}{$\mathrm{Zr}$} & GBC (ppt) & $<\mathrm{LOQ}_{\mathrm{Zn}}$ & $<\mathrm{LOQ}_{\mathrm{Zn}}$ & $3718 \pm 186$ & $3416 \pm 171$ & $2169 \pm 108$ & $1493 \pm 75$ & $1345 \pm 67$ \\
\hline & QD-LOQ (ppt) & 10 & 7 & 39 & 139 & 118 & 64 & 112 \\
\hline & Precision (ppt) & 0.8 & 1 & 8 & 27 & 42 & 38 & 23 \\
\hline & QD-RLOQ & - & - & $1.0 \%$ & $3.9 \%$ & $5.2 \%$ & $4.1 \%$ & $7.7 \%$ \\
\hline \multirow{5}{*}{$\mathrm{Cd}$} & GBC (ppt) & $<\mathrm{LOQ}_{\mathrm{Cd}}$ & $<\mathrm{LOQ}_{\mathrm{Cd}}$ & $8.4 \pm 0.4$ & $23 \pm 1.2$ & $42 \pm 2.1$ & $81 \pm 4.0$ & $75 \pm 3.8$ \\
\hline & QD-LOQ (ppt) & 0.31 & 1.9 & 3.4 & 22 & 39 & 76 & 62 \\
\hline & Precision (ppt) & 0.11 & 0.30 & 0.78 & 7.5 & 8.9 & 14 & 10 \\
\hline & QD-RLOQ & - & - & $29 \%$ & $49 \%$ & $48 \%$ & $48 \%$ & $45 \%$ \\
\hline & GBC (ppt) & $<\mathrm{LOQ}_{\mathrm{Se}}$ & n.a. & $1069 \pm 53$ & $933 \pm 47$ & $649 \pm 33$ & $617 \pm 31$ & $683 \pm 34$ \\
\hline & QD-LOQ (ppt) & 6 & n.a. & 132 & 1044 & 2534 & 2003 & 1689 \\
\hline \multirow{2}{*}{ Sc } & Precision (ppt) & 0.4 & n.a. & 5 & 25 & 64 & 36 & 36 \\
\hline & QD-RLOQ & - & - & $11 \%$ & $53 \%$ & $80 \%$ & $77 \%$ & $71 \%$ \\
\hline
\end{tabular}

343

344 Unsurprisingly in light of the poor recovery rates observed for Se, QD-LOQSe are one order of

345 magnitude higher on average than QD-LOQZn and QD-LOQCd. An ANOVA calculation confirmed

346 that the ICP resolution significantly affects the QD-LOQ at the 99\% confidence level (Tables S9

347 and S11, model M2). In the following, the QD-LOQs according to Se will not be further discussed. 
348 For Cd and Zn tracers, QD-LOQs have mean values of 29 and 70 ppt. However, the QD-LOQs in

349 complex matrices (Seine, sea and estuarine waters) are 37 and 11 times those observed in simple

350 matrices $\left(\mathrm{HNO}_{3}\right.$ and $\left.\mathrm{NaNO}_{3}\right)$ for $\mathrm{Cd}$ and $\mathrm{Zn}$ respectively. Despite this one-order-of-magnitude

351 increase, the multispiked QDs can be detected in realistic surface water samples in concentrations

352 as low as $41 \mathrm{ppt}$ in $\mathrm{Cd}$ and $95 \mathrm{ppt}$ in $\mathrm{Zn}$ on average, which are about 3 to 6 order of magnitudes

353 lower than the typical concentrations used in ENPs dissemination and toxicity studies (ppb-ppm

354 level) ${ }^{36,51-53}$ These results demonstrate the significant added value of the isotopic labelling

355 technique in order to model the environmental fate of ENPs in conditions mimicking as best as

356 possible the natural media.

357 The increase of the QD-LOQs in complex matrices compared to the ones in simplified media

358 could be explained by three possible arguments. First, simplified media contain virtually zero

359 geochemical background contribution of the spike elements. Indeed, the concentrations in $\mathrm{Cd}$ and

$360 \mathrm{Zn}$ in the blank samples in the case of $\mathrm{HNO}_{3}$ and $\mathrm{NaNO}_{3}$ were below the $\mathrm{LOQs}$ for their respective

361 isotopes. When moving from these simple media to complex matrices, geochemical background

$362 \mathrm{Cd}$ and $\mathrm{Zn}$ concentrations increase up to $75 \mathrm{ppt}$ (in sea water) and $3.7 \mathrm{ppb}$ (in Seine water), that is

36311 and 3.5 times more than the upper limit of the QD concentration ranges that were investigated

364 in this study. Therefore, the characteristic isotopic fingerprint of the multispiked QDs gets diluted

365 into a large geochemical contribution having the natural isotopic pattern of abundances. This effect

366 will be looked into using the geochemical background concentrations (GBC) of the tracer element

367 in each sample.

368 Second, complex matrices contain a high concentration of dissolved salts. These can affect 369 intensity readings compared to readings that would have been observed at equal tracer 
370 concentration in $\mathrm{HNO}_{3}$, which is the matrix in which the $I\left({ }^{A} X\right) v s . C_{A}$ calibration plots were

371 acquired, in a phenomenon known as matrix effect ${ }^{46}$ which will be investigated using the ionic

372 strength in the solutions analyzed in the instrument as metric.

373 Finally, the sea water and estuarine water samples contain high dissolved salt concentrations

374 (Table S2, total dissolved solids $\mathrm{TDS}_{\mathrm{Sw}}=40.8 \mathrm{~g} / \mathrm{L}, \mathrm{I}=0.69 \mathrm{M}$ ) that may damage the instrument

375 and drastically decrease its sensitivity. These samples had to be diluted prior to ICP-MS analysis,

376 to reach at most the maximum recommended TDS values for ICP-MS analysis $(2 \mathrm{~g} / \mathrm{L})^{47,54}$ resulting

377 in lower tracer concentrations and therefore to lower count numbers. This last effect will be 378 examined using the dilution factor applied to each sample.

379 On Figure 5, the QD-LOQs according to $\mathrm{Cd}$ and $\mathrm{Zn}$ tracers were plotted along with the 380 geochemical background concentrations for each matrix and the ionic strength (after dilution if any

381 was required), with an indication of the dilution factor that was applied before ICP-MS analysis.

382 First, the ionic strength of the solutions analyzed in ICP-MS appears constant throughout the 383 various matrices because the acidification at $2 \% \mathrm{HNO}_{3}$ prior to analysis levels it in all analyzed 384 samples. Therefore, matrix effects cannot account for the increase in QD-LOQs observed when 385 moving from simple media to complex aquatic matrices. Second, for both $\mathrm{Cd}$ and $\mathrm{Zn}$, the lowest 386 QD-LOQs are the one determined in matrices that did not necessitate dilution prior analysis, so the 387 dilution factor seems to have a significant impact on the QD-LOQ. Last, when Cd is used as a 388 tracer, the QD-LOQs seem to strongly correlate with the GBC. To confirm these graphical findings, 389 ANOVA calculations were conducted. When attempting to model the whole set of QD-LOQs for $390 \mathrm{Cd}$ and $\mathrm{Zn}$, it was found that only the dilution factor and GBC were significant at the $99 \%$ 391 confidence level (model M3, Table S12). The QD-LOQs based on Zn were found to depend only 
392 on the dilution factor (model M4, Table S13, Figure S25), while those based on Cd had a strong 393 and exclusive correlation with the GBC (model M5, Table S14, Figure S26). These results are in 394 line with the instrumental constraints pertaining to the $\mathrm{Zn}$ and $\mathrm{Cd}$ detection. As $\mathrm{Zn}$ is analyzed in 395 MR for which signal intensity is on the order of $10 \%$ of that of LR measurements, it is expected to 396 be more strongly impacted by further shrinking of the count numbers upon dilution than $\mathrm{Cd}$. On 397 the other hand, the LR measurements in the case of Cd have a smaller discrimination power 398 between isotopes: ${ }^{110} \mathrm{Cd}$ and ${ }^{111} \mathrm{Cd}$ are less distinct in LR than ${ }^{66} \mathrm{Zn}$ and ${ }^{68} \mathrm{Zn}$ in $\mathrm{MR}$, all the more 399 since the latter are separated by two units of mass number. In the presence of increasing GBC of $400 \mathrm{Cd}$ with natural abundance, the ${ }^{111} \mathrm{Cd} /{ }^{10} \mathrm{Cd}$ ratio is damped, which may result in impaired 401 estimation of the ${ }^{111} \mathrm{Cd}$ contribution. 

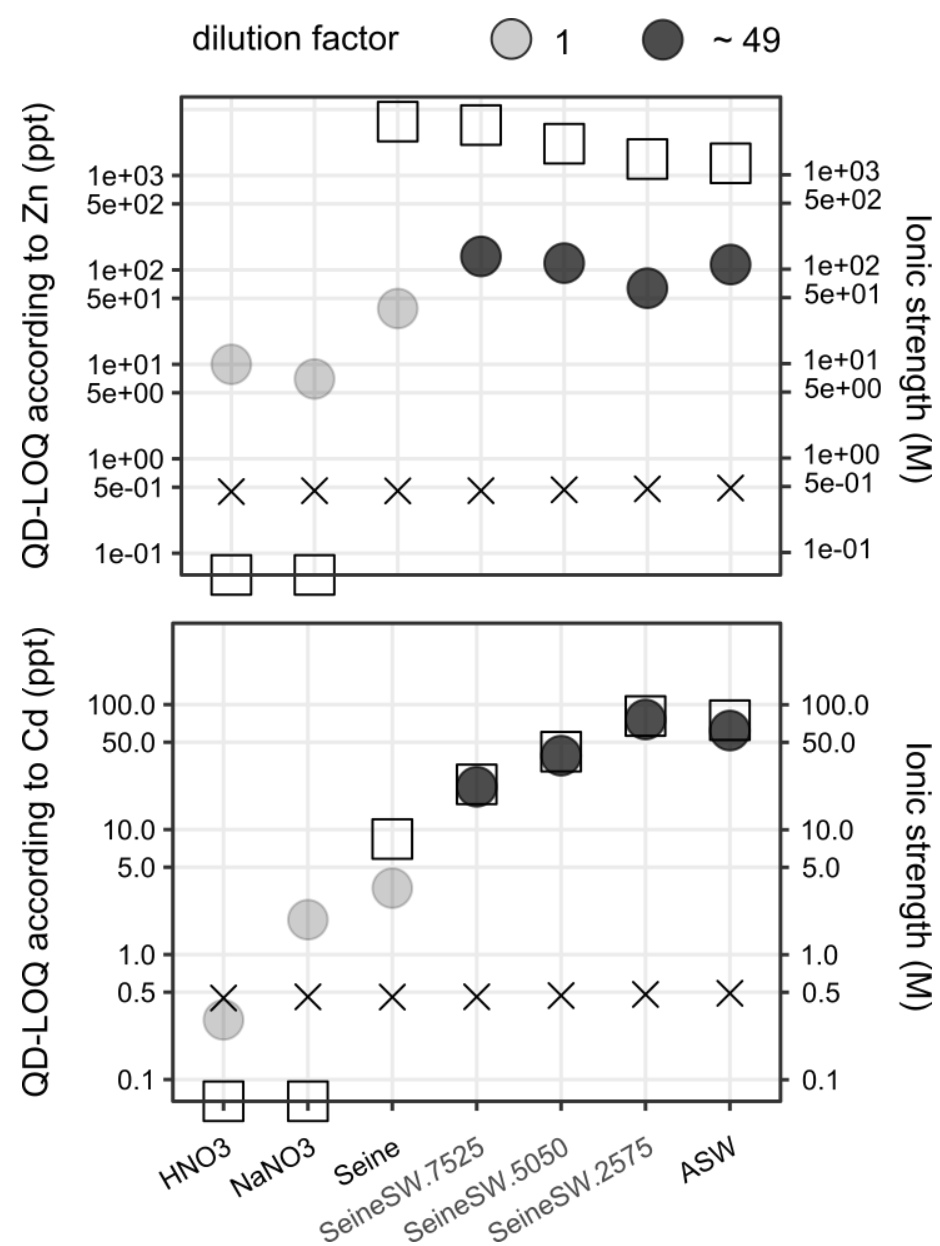

404 Figure 5. Limits of quantification of multi-spiked QDs (QD-LOQs, dots, in ppt), geochemical 405 background concentration (GBC, squares, also in ppt), ionic strength of the solutions as analyzed 406 in ICP-MS (crosses, in moles. $\mathrm{L}^{-1}$ ) and dilution factor applied prior to ICP analysis (mapped to the 407 transparency of the dot symbols) in the various aquatic matrices, according to the $\mathrm{Zn}$ tracer (top) 408 and to the Cd tracer (bottom). 
410 Therefore, the QD-LOQs can be affected by the GBC in the matrices, dilution factor, and analysis

411 resolution. Hence, the relevance of the isotopic spiking method will depend on the element and the

412 matrix targeted in the study. These factors should be considered, for example when choosing the

413 concentration of spiked QDs (or spiked $\mathrm{Zn} / \mathrm{Cd} / \mathrm{Se}$-containing ENPs) to be used in studies related

414 to ENPs fate and behavior.

415 To summarize, the limits of quantifications of isotopically labelled CdSe/ZnS quantum dots (QD-

416 LOQs) in natural aquatic matrices were accurately determined by combining HR-ICP-MS and

417 chemometric analysis. QD-LOQs were found varying between 3.4 and $2500 \mathrm{ppt}$ according to the

418 element and the aquatic matrix, which is within the range of ENPs concentrations that are expected

419 in natural surface waters (e.g. 2000, 170, and 100, and <10 ppt for $\mathrm{TiO}_{2}, \mathrm{ZnO}, \mathrm{Ag}$, and QDs NPs

420 respectively). ${ }^{23,40,41,55-58}$ Furthermore, our results indicate that the use of isotopic labelling of ENPs

421 coupled with HR-ICP-MS allows to work at ENPs concentrations about 3 to 6 orders of magnitude

422 lower than the typical concentrations used in numerous ENPs fate and toxicity studies (e.g. ZnO at

423100 ppb-163 ppm, QDs at 60-3600 ppb). ${ }^{26,27,29,51-53}$ Finally, this method does not require the

424 commonly employed feature (e.g. optical emission) for fluorescent ENPs such as QDs, which

425 photoluminescent properties can easily be quenched. The QD-LOQs calculated in the present study

426 are up to 2 orders of magnitude more sensitive than methods based on QDs photoluminescence

427 measurement. ${ }^{59}$

428

429 Perspective: Relative QD-LOQ

430 Remarkably, the order of magnitude of relative QD-LOQ (or QD-RLOQ), expressed as the ratio 431 of the QD-LOQ to the sum of QD-LOQ and the total natural element concentration already present 
432 in the matrix (Eq. 2) seems to be characteristic of a given element (Table 1). This variability could

433 then be used to draw estimations of the QD-LOQs in matrices not investigated in the present study, 434 provided that the GBC of that new matrix is known. The knowledge of an expected order of 435 magnitude for the QD-LOQ enables to choose the lowest, and therefore closest to the natural media, 436 concentration of QDs to work with in model dissemination experiments, so as to be able to harvest 437 quantitative data by HR-ICP-MS from said experiments. We recommend though to choose such 438 working QD concentration bearing in mind that due to aggregation phenomena, not all 439 disseminated QDs will actually dissolve.

$440 \quad Q D R L O Q=\frac{Q D L O Q}{Q D L O Q+G B C} * 100$ Eq. 2

441 This percentage allows to accurately assess the efficiency of the spiking method by considering 442 the GBC in the matrix. Globally, we propose that the RLOQ values defined in the present study 443 can be further used to determine the concentration of $\mathrm{Zn} / \mathrm{Cd} / \mathrm{Se}$-containing ENPs to be used in any 444 experiment related to their fate/behavior/toxicity by using isotopic labelling technique. However, 445 one should consider a slightly higher ENPs concentration when studying their dissolution since the 446 dissolved ENPs concentration is initially unknown. For instance, if $\mathrm{Zn}$ from Zn-containing ENPs 447 is expected to dissolve at most $50 \%$, the ENPs concentration used should be at least 2 times the 448 QD-LOQ. Future studies related to ENPs fate, behavior, and toxicity in aquatic environments 449 should be, as much as possible, carried out at environmentally relevant concentrations through the 450 use of isotopically labelled ENPs, on the basis of the QD-LOQs estimated in the present study. The 451 use of relevant concentrations in future experimental work should result in a better and accurate 452 understanding on the ENPs fate, behavior, and toxicity. 453 


\section{Supporting Information}

456 Compositions of aquatic matrices (Tables S1 and S2), Acid digestion protocol, Calculations of

457 spiked QDs concentrations for Zn, Cd, and Se, Absorption and emission spectra of the test run QDs 458 (Figure S1), QDs characterization images (Figure S2), Isotopic composition of multispiked QDs 459 (Figure S3), Daily determination of the conventional HR-ICP-MS limit of quantification (LOQ) 460 and its standard error (Figure S4), HR-ICP-MS calibration and spiked QDs concentration recovery 461 plots (Figures S5 to S24), bias of the recovery plots (Table S3), $t$ table (Table S4), calculated 462 statistic $t$ values (Table S5 to S7), ANOVA test tables (Table S8 to S14) and correlation figures 463 (Figures S25 and S26).

464 This material is available free of charge via the Internet at http://pubs.acs.org

466 AUTHOR INFORMATION

467 Corresponding author

468 *Email: sivry@ipgp.fr

\section{Author Contributions}

470 The manuscript was written through contributions of all authors. All authors have given approval 471 to the final version of the manuscript. ${ }^{\dagger} \star \Delta$ These authors contributed equally. 


\section{Funding Sources}

473 This research project (nanospike.fr) was fully supported by the French Agency for Food,

474 Environmental and Occupational Health \& Safety (ANSES) under the convention $\mathrm{N}^{\circ}$ EST475 2013/1/264. Part of this work was supported by the IPGP multidisciplinary program PARI and by 476 Paris-IdF region SESAME Grant ${ }^{\circ} 12015908$.

$477 \quad$ Notes

478 The authors declare no competing financial interest.

480 ABBREVIATIONS

481 ENPs, engineered nanoparticles; FWHM, full width at half maximum; GBC, geochemical 482 background concentrations; QDs, quantum dots, QD-LOQ, limit of quantification of spiked QDs 483 according to the element labelled and to the matrix composition; QD-RLOQ, relative QD-LOQ.

485 ACKNOWLEDGEMENT

486 Our thanks go out to the team technical staff, especially to Mr. Mickaël Tharaud and Ms. Laure 487 Cordier, for the assistance during various multi-elemental analyses. Parts of this work were 488 supported by IPGP multidisciplinary program PARI, and by Paris-IdF region SESAME Grant no. 48912015908. 
(1) Mitrano, D. M.; Motellier, S.; Clavaguera, S.; Nowack, B. Review of Nanomaterial Aging and Transformations through the Life Cycle of Nano-Enhanced Products. Environ. Int. 2015, 77, 132-147. https://doi.org/10.1016/j.envint.2015.01.013.

(2) Lan, Y.; Lu, Y.; Ren, Z. Mini Review on Photocatalysis of Titanium Dioxide Nanoparticles and Their Solar Applications. Nano Energy 2013, 2 (5), 1031-1045. https://doi.org/10.1016/j.nanoen.2013.04.002.

(3) Contado, C. Nanomaterials in Consumer Products: A Challenging Analytical Problem. Front. Chem. 2015, 3, 48, 1-20. https://doi.org/10.3389/fchem.2015.00048.

(4) Calzolai, L.; Gilliland, D.; Rossi, F. Measuring Nanoparticles Size Distribution in Food and Consumer Products: A Review. Food Addit. Contam. Part A 2012, 29 (8), 1183-1193. https://doi.org/10.1080/19440049.2012.689777.

(5) Mattarozzi, M.; Suman, M.; Cascio, C.; Calestani, D.; Weigel, S.; Undas, A.; Peters, R. Analytical Approaches for the Characterization and Quantification of Nanoparticles in Food and Beverages. Anal. Bioanal. Chem. 2017, 409 (1), 63-80. https://doi.org/10.1007/s00216016-9946-5.

(6) Yetisen, A. K.; Qu, H.; Manbachi, A.; Butt, H.; Dokmeci, M. R.; Hinestroza, J. P.; Skorobogatiy, M.; Khademhosseini, A.; Yun, S. H. Nanotechnology in Textiles. ACS Nano 2016, 10 (3), 3042-3068. https://doi.org/10.1021/acsnano.5b08176.

(7) Chernousova, S.; Epple, M. Silver as Antibacterial Agent: Ion, Nanoparticle, and Metal. Angew. Chem. Int. Ed. 2013, 52 (6), 1636-1653. https://doi.org/10.1002/anie.201205923.

(8) Samsung Electronics. Samsung Silver Nano Technology, Refigerator Silver Nano, Washing Machine Silver Nano, Air Conditioner Silver Nano http://www.samsung.com/my/consumer/learningresources/silvernano/silvernano/ (accessed Sep 2, 2017).

(9) Mitrano, D. M.; Ranville, J. F.; Bednar, A.; Kazor, K.; Hering, A. S.; Higgins, C. P. Tracking Dissolution of Silver Nanoparticles at Environmentally Relevant Concentrations in Laboratory, Natural, and Processed Waters Using Single Particle ICP-MS (SpICP-MS). Environ. Sci. Nano 2014, 1 (3), 248-259. https://doi.org/10.1039/C3EN00108C.

(10) Kühn, M.; Ivleva, N. P.; Klitzke, S.; Niessner, R.; Baumann, T. Investigation of Coatings of Natural Organic Matter on Silver Nanoparticles under Environmentally Relevant Conditions by Surface-Enhanced Raman Scattering. Sci. Total Environ. 2015, 535, 122-130. https://doi.org/10.1016/j.scitotenv.2014.12.026.

(11) Ibrahim, H. M. M.; Hassan, M. S. Characterization and Antimicrobial Properties of Cotton Fabric Loaded with Green Synthesized Silver Nanoparticles. Carbohydr. Polym. 2016, 151, 841-850. https://doi.org/10.1016/j.carbpol.2016.05.041.

(12) Mackevica, A.; Olsson, M. E.; Hansen, S. F. The Release of Silver Nanoparticles from Commercial Toothbrushes. J. Hazard. Mater. 2017, 322, Part A, 270-275. https://doi.org/10.1016/j.jhazmat.2016.03.067.

(13) Tyagi, N.; Srivastava, S. K.; Arora, S.; Omar, Y.; Ijaz, Z. M.; AL-Ghadhban, A.; Deshmukh, S. K.; Carter, J. E.; Singh, A. P.; Singh, S. Comparative Analysis of the Relative Potential of Silver, Zinc-Oxide and Titanium-Dioxide Nanoparticles against UVB-Induced DNA 
(14) Wiechers, J. W.; Musee, N. Engineered Inorganic Nanoparticles and Cosmetics: Facts, Issues, Knowledge Gaps and Challenges. J. Biomed. Nanotechnol. 2010, 6 (5), 408-431. https://doi.org/10.1166/jbn.2010.1143.

(15) Newman, M. D.; Stotland, M.; Ellis, J. I. The Safety of Nanosized Particles in Titanium Dioxide- and Zinc Oxide-Based Sunscreens. J. Am. Acad. Dermatol. 2009, 61 (4), 685-692. https://doi.org/10.1016/j.jaad.2009.02.051.

(16) Senanayake, S. D.; Stacchiola, D.; Rodriguez, J. A. Unique Properties of Ceria Nanoparticles Supported on Metals: Novel Inverse Ceria/Copper Catalysts for CO Oxidation and the Water-Gas Shift Reaction. Acc. Chem. Res. 2013, 46 (8), 1702-1711. https://doi.org/10.1021/ar300231p.

(17) Dai, X.; Deng, Y.; Peng, X.; Jin, Y. Quantum-Dot Light-Emitting Diodes for Large-Area Displays: Towards the Dawn of Commercialization. Adv. Mater. Deerfield Beach Fla 2017, 29 (14). https://doi.org/10.1002/adma.201607022.

(18) Nann, T.; Skinner, W. M. Quantum Dots for Electro-Optic Devices. ACS Nano 2011, 5 (7), 5291-5295. https://doi.org/10.1021/nn2022974.

(19) Pickering, S.; Kshirsagar, A.; Ruzyllo, J.; Xu, J. Patterned Mist Deposition of Tri-Colour CdSe/ZnS Quantum Dot Films toward RGB LED Devices. Opto-Electron. Rev. 2012, 20 (2), 148-152. https://doi.org/10.2478/s11772-012-0019-9.

(20) Shirasaki, Y.; Supran, G. J.; Bawendi, M. G.; Bulović, V. Emergence of Colloidal QuantumDot Light-Emitting Technologies. Nat. Photonics 2013, 7 (1), 13-23. https://doi.org/10.1038/nphoton.2012.328.

(21) Kamat, P. V. Quantum Dot Solar Cells. The Next Big Thing in Photovoltaics. J. Phys. Chem. Lett. 2013, 4 (6), 908-918. https://doi.org/10.1021/jz400052e.

(22) Chuang, C.-H. M.; Brown, P. R.; Bulović, V.; Bawendi, M. G. Improved Performance and Stability in Quantum Dot Solar Cells through Band Alignment Engineering. Nat. Mater. 2014, 13 (8), 796-801. https://doi.org/10.1038/nmat3984.

(23) Gottschalk, F.; Sonderer, T.; Scholz, R. W.; Nowack, B. Modeled Environmental Concentrations of Engineered Nanomaterials (TiO2, $\mathrm{ZnO}, \mathrm{Ag}, \mathrm{CNT}$, Fullerenes) for Different Regions. Environ. Sci. Technol. 2009, 43 (24), 9216-9222. https://doi.org/10.1021/es9015553.

(24) Domingos, R. F.; Tufenkji, N.; Wilkinson, K. J. Aggregation of Titanium Dioxide Nanoparticles: Role of a Fulvic Acid. Environ. Sci. Technol. 2009, 43 (5), 1282-1286. https://doi.org/10.1021/es8023594.

(25) Collin, B.; Auffan, M.; Johnson, A. C.; Kaur, I.; Keller, A. A.; Lazareva, A.; Lead, J. R.; Ma, X.; Merrifield, R. C.; Svendsen, C.; Whitej, J. C..; Unrine, J. M. Environmental Release, Fate and Ecotoxicological Effects of Manufactured Ceria Nanomaterials. Environ. Sci.: Nano 2014, 1 (6), 533-548. https://doi.org/10.1039/C4EN00149D.

(26) Sivry, Y.; Gelabert, A.; Cordier, L.; Ferrari, R.; Lazar, H.; Juillot, F.; Menguy, N.; Benedetti, M. F. Behavior and Fate of Industrial Zinc Oxide Nanoparticles in a Carbonate-Rich River Water. Chemosphere 2014, 95, 519-526. https://doi.org/10.1016/j.chemosphere.2013.09.110. 
576

577

578

579

580

581

582

583

584

585

586

587

588

589

590

591

592

593

594

595

596

597

598

599

600

601

602

603

604

605

606

607

608

609

610

611

612

613

614

615

616

617

618

(27) Gelabert, A.; Sivry, Y.; Ferrari, R.; Akrout, A.; Cordier, L.; Nowak, S.; Menguy, N.; Benedetti, M. F. Uncoated and Coated ZnO Nanoparticle Life Cycle in Synthetic Seawater. Environ. Toxicol. Chem. 2014, 33 (2), 341-349. https://doi.org/10.1002/etc.2447.

(28) Conway, J. R.; Adeleye, A. S.; Gardea-Torresdey, J.; Keller, A. A. Aggregation, Dissolution, and Transformation of Copper Nanoparticles in Natural Waters. Environ. Sci. Technol. 2015, 49 (5), 2749-2756. https://doi.org/10.1021/es504918q.

(29) Rocha, A. D.; Sivry, Y.; Gelabert, A.; Beji, Z.; Benedetti, M. F.; Menguy, N.; Brayner, R. The Fate of Polyol-Made ZnO and CdS Nanoparticles in Seine River Water (Paris, France). J. Nanosci. Nanotechnol. 2015, 15 (5), 3900-3908. https://doi.org/10.1166/jnn.2015.9276.

(30) Furtado, L. M.; Bundschuh, M.; Metcalfe, C. D. Monitoring the Fate and Transformation of Silver Nanoparticles in Natural Waters. Bull. Environ. Contam. Toxicol. 2016, 97 (4), 449455. https://doi.org/10.1007/s00128-016-1888-2.

(31) Yung, M. M. N.; Wong, S. W. Y.; Kwok, K. W. H.; Liu, F. Z.; Leung, Y. H.; Chan, W. T.; Li, X. Y.; Djurišić, A. B.; Leung, K. M. Y. Salinity-Dependent Toxicities of Zinc Oxide Nanoparticles to the Marine Diatom Thalassiosira Pseudonana. Aquat. Toxicol. 2015, 165, 31-40. https://doi.org/10.1016/j.aquatox.2015.05.015.

(32) Keller, A. A.; Wang, H.; Zhou, D.; Lenihan, H. S.; Cherr, G.; Cardinale, B. J.; Miller, R.; Ji, Z. Stability and Aggregation of Metal Oxide Nanoparticles in Natural Aqueous Matrices. Environ. Sci. Technol. 2010, 44 (6), 1962-1967. https://doi.org/10.1021/es902987d.

(33) Dybowska, A. D.; Croteau, M.-N.; Misra, S. K.; Berhanu, D.; Luoma, S. N.; Christian, P.; O’Brien, P.; Valsami-Jones, E. Synthesis of Isotopically Modified ZnO Nanoparticles and Their Potential as Nanotoxicity Tracers. Environ. Pollut. 2011, 159 (1), 266-273. https://doi.org/10.1016/j.envpol.2010.08.032.

(34) Buffet, P.-E.; Amiard-Triquet, C.; Dybowska, A.; Risso-de Faverney, C.; Guibbolini, M.; Valsami-Jones, E.; Mouneyrac, C. Fate of Isotopically Labeled Zinc Oxide Nanoparticles in Sediment and Effects on Two Endobenthic Species, the Clam Scrobicularia Plana and the Ragworm Hediste Diversicolor. Ecotoxicol. Environ. Saf. 2012, 84, 191-198. https://doi.org/10.1016/j.ecoenv.2012.07.010.

(35) Larner, F.; Dogra, Y.; Dybowska, A.; Fabrega, J.; Stolpe, B.; Bridgestock, L. J.; Goodhead, R.; Weiss, D. J.; Moger, J.; Lead, J. R.; Valsami-Jones, E.; Tyler, C. R.; Galloway, T. S.; Rehkämper, M. Tracing Bioavailability of $\mathrm{ZnO}$ Nanoparticles Using Stable Isotope Labeling. Environ. Sci. Technol. 2012, 46 (21), 12137-12145. https://doi.org/10.1021/es302602j.

(36) Khan, F. R.; Laycock, A.; Dybowska, A.; Larner, F.; Smith, B. D.; Rainbow, P. S.; Luoma, S. N.; Rehkaemper, M.; Valsami-Jones, E. Stable Isotope Tracer To Determine Uptake and Efflux Dynamics of ZnO Nano- and Bulk Particles and Dissolved $\mathrm{Zn}$ to an Estuarine Snail. Environ. Sci. Technol. 2013, 47 (15), 8532-8539. https://doi.org/10.1021/es4011465.

(37) Laycock, A.; Diez-Ortiz, M.; Larner, F.; Dybowska, A.; Spurgeon, D.; Valsami-Jones, E.; Rehkaemper, M.; Svendsen, C. Earthworm Uptake Routes and Rates of Ionic Zn and ZnO Nanoparticles at Realistic Concentrations, Traced Using Stable Isotope Labeling. Environ. Sci. Technol. 2016, 50 (1), 412-419. https://doi.org/10.1021/acs.est.5b03413.

(38) Bourgeault, A.; Cousin, C.; Geertsen, V.; Cassier-Chauvat, C.; Chauvat, F.; Durupthy, O.; Chanéac, C.; Spalla, O. The Challenge of Studying TiO2 Nanoparticle Bioaccumulation at 
619

Environmental Concentrations: Crucial Use of a Stable Isotope Tracer. Environ. Sci. Technol. 2015, 49 (4), 2451-2459. https://doi.org/10.1021/es504638f.

(39) Croteau, M.-N.; Dybowska, A. D.; Luoma, S. N.; Misra, S. K.; Valsami-Jones, E. Isotopically Modified Silver Nanoparticles to Assess Nanosilver Bioavailability and Toxicity at Environmentally Relevant Exposures. Environ. Chem. 2014, 11 (3), 247-256. https://doi.org/10.1071/EN13141.

(40) Gottschalk, F.; Lassen, C.; Kjoelholt, J.; Christensen, F.; Nowack, B. Modeling Flows and Concentrations of Nine Engineered Nanomaterials in the Danish Environment. Int. J. Environ. Res. Public. Health 2015, 12 (5), 5581-5602. https://doi.org/10.3390/ijerph120505581.

(41) Piccinno, F.; Gottschalk, F.; Seeger, S.; Nowack, B. Industrial Production Quantities and Uses of Ten Engineered Nanomaterials in Europe and the World. J. Nanoparticle Res. 2012, 14 (9), 1-11. https://doi.org/10.1007/s11051-012-1109-9.

(42) Majedi, S. M.; Lee, H. K.; Kelly, B. C. Chemometric Analytical Approach for the Cloud Point Extraction and Inductively Coupled Plasma Mass Spectrometric Determination of Zinc Oxide Nanoparticles in Water Samples. Anal. Chem. 2012, 84 (15), 6546-6552. https://doi.org/10.1021/ac300833t.

(43) Benedetti, M. F.; Dia, A.; Riotte, J.; Chabaux, F.; Gérard, M.; Boulègue, J.; Fritz, B.; Chauvel, C.; Bulourde, M.; Déruelle, B.; Ildefonse, P. Chemical Weathering of Basaltic Lava Flows Undergoing Extreme Climatic Conditions: The Water Geochemistry Record. Chem. Geol. 2003, 201 (1-2), 1-17. https://doi.org/10.1016/S0009-2541(03)00231-6.

(44) Seine Normandie Water Agency. Etude 2008 - Guide toxique (Zn, Cd, Se) http://www.eauseine-normandie.fr.

(45) Bae, W. K.; Char, K.; Hur, H.; Lee, S. Single-Step Synthesis of Quantum Dots with Chemical Composition Gradients. Chem. Mater. 2008, 20 (2), 531-539. https://doi.org/10.1021/cm070754d.

(46) Garrels, R. M.; Christ, C. L. Solutions, Minerals, and Equilibria; Harper \& Row, 1965.

(47) McCurdy, E.; Proper, W. Improving ICP-MS Analysis of Samples Containing High Levels of Total Dissolved Solids. Spectroscopy. 2014.

(48) Thomas, R. A Beginner's Guide to ICP-MS Part XII - A Review of Interferences. Spectroscopy 2002, 17 (10).

(49) Casadevall, A.; Fang, F. C. Reproducible Science. Infect. Immun. 2010, 78 (12), 4972-4975. https://doi.org/10.1128/IAI.00908-10.

(50) Far, J.; Bérail, S.; Preud'homme, H.; Lobinski, R. Determination of the Selenium Isotopic Compositions in Se-Rich Yeast by Hydride Generation-Inductively Coupled Plasma Multicollector Mass Spectrometry. J. Anal. At. Spectrom. 2010, 25 (11), 1695-1703. https://doi.org/10.1039/C004933F.

(51) Tang, Y.; Li, S.; Lu, Y.; Li, Q.; Yu, S. The Influence of Humic Acid on the Toxicity of Nano-ZnO and Zn2+ to the Anabaena Sp. Environ. Toxicol. 2015, 30 (8), 895-903. https://doi.org/10.1002/tox.21964.

(52) Jackson, B. P.; Bugge, D.; Ranville, J. F.; Chen, C. Y. Bioavailability, Toxicity, and Bioaccumulation of Quantum Dot Nanoparticles to the Amphipod Leptocheirus Plumulosus. Environ. Sci. Technol. 2012, 46 (10), 5550-5556. https://doi.org/10.1021/es202864r. 
662

663

664

665

666

667

668

669

670

671

672

673

674

675

676

677

678

679

680

681

682

683

684

685
(53) Xiao, Y.; Ho, K. T.; Burgess, R. M.; Cashman, M. Aggregation, Sedimentation, Dissolution, and Bioavailability of Quantum Dots in Estuarine Systems. Environ. Sci. Technol. 2017, 51 (3), 1357-1363. https://doi.org/10.1021/acs.est.6b04475.

(54) Thermo Fischer. Thermo Fischer Scientific, Application Note 30003, Determination Trace Elements Clinical Samples High-Resolution-ICP-MS; 2007.

(55) Gottschalk, F.; Sun, T.; Nowack, B. Environmental Concentrations of Engineered Nanomaterials: Review of Modeling and Analytical Studies. Environ. Pollut. 2013, 181, 287-300. https://doi.org/10.1016/j.envpol.2013.06.003.

(56) Gottschalk, F.; Ort, C.; Scholz, R. W.; Nowack, B. Engineered Nanomaterials in Rivers Exposure Scenarios for Switzerland at High Spatial and Temporal Resolution. Environ. Pollut. 2011, 159 (12), 3439-3445. https://doi.org/10.1016/j.envpol.2011.08.023.

(57) Tiede, K.; Hassellöv, M.; Breitbarth, E.; Chaudhry, Q.; Boxall, A. B. A. Considerations for Environmental Fate and Ecotoxicity Testing to Support Environmental Risk Assessments for Engineered Nanoparticles. J. Chromatogr. A 2009, 1216 (3), 503-509. https://doi.org/10.1016/j.chroma.2008.09.008.

(58) Dumont, E.; Johnson, A. C.; Keller, V. D. J.; Williams, R. J. Nano Silver and Nano ZincOxide in Surface Waters - Exposure Estimation for Europe at High Spatial and Temporal Resolution. Environ. Pollut. 2015, 196, 341-349. https://doi.org/10.1016/j.envpol.2014.10.022.

(59) Xu, S.; Wang, C.; Xu, Q.; Li, R.; Shao, H.; Zhang, H.; Fang, M.; Lei, W.; Cui, Y. What Is a Convincing Photoluminescence Quantum Yield of Fluorescent Nanocrystals. J. Phys. Chem. C 2010, 114 (34), 14319-14326. https://doi.org/10.1021/jp100696e. 
686

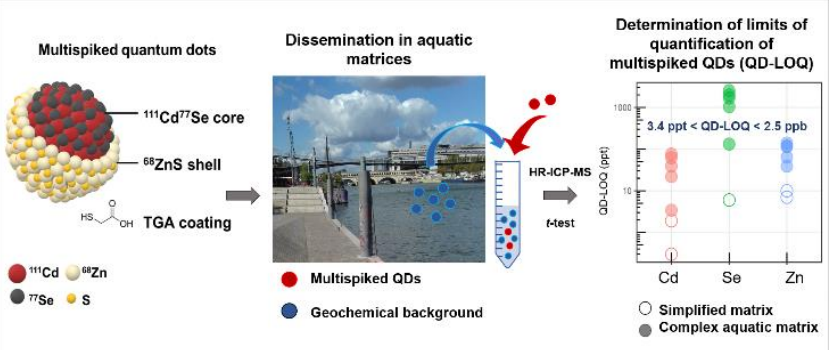

687

688 For Table of Contents Only 